\section{A HISTORICAL STUDY OF TIME MARKERS IN THAI $^{1}$}

\section{Pranee Kullavanijaya $^{2}$}

\begin{abstract}
In general, time markers which mark a sequence of events can be divided into two main types: markers that have locution time of utterance as the referential point, and markers that have the mentioned time in the text as the referential point. Both types of markers range from one word which can be either inherent or derived to such constructions as noun phrases and preposition phrases. The study shows an increase in both the derived words and phrasal constructions in the four studied periods: Sukhothai, Ayutthaya, Mid-Rattanakosin and Modern Thai.
\end{abstract}

The study also shows that two types of metaphors, one of moving time and standing time, are used in the four periods with an increase of varieties in each of the periods. Time expressions such as /wan33 naa42/ 'day-front' and /wan33 lan24/ 'day-back' are good examples of metaphors of standing time and moving time respectively, both used to mean the future in Modern Thai.

'This paper was originally presented at SEAL XIII conference in May 2003.

${ }^{2}$ Ph.D., Emeritus Professor, Faculty of Arts, Chulalongkorn University, Bangkok, Thailand.

\section{Introduction}

To understand an event fully, one has to locate it in real time. Such a calendric expression as 'at 8 a.m. on the first of May 2003' can best fulfill the location task. However, in real life, for the purpose of everyday communication, one does not always want such an exact time to locate all events. Instead, one usually wants to understand an event in relation to another event, whether it occurs before or after that event or at the same time. When we talk about the time of an event in relation to a certain point of time or a temporal reference point, we are talking about time deixis.

According to Fillmore (1997), time deixis refers to the time at which the communication act takes place. Linguistic time markers or time expressions as the formal properties for the time deixis include both calendric expressions such as $8 o^{\prime}$ 'clock, today, the past ten years, and non-calendric expressions which range from bound morphemes known as tense to lexical items and composite lexical constructions such as now, then, this, that, when, in the past. This paper deals with noncalendric expressions excluding tense which is not used in Thai. These time expressions will be referred to as deictic time markers or sometimes time markers.

The paper studies deictic time markers within a limit of a simple sentence and a subordinating clause in a complex sentence. Its purpose is first to examine the structure of the deictic time markers; secondly, to group the time markers into semantic types on the basis of their relation to the present moment or in relation to another event; and thirdly, to study how time markers reveal the 
concept of time in Thai. Since materials studied are drawn from the four periods: Sukhothai (SK) (1283-1350), Ayutthaya (AY) (1350-1767), Mid-Rattanakosin (RN) (1851-1910), and Modern Thai (MT), a historical study is therefore taken into account.

It will be assumed that materials of all four periods are phonologically more or less of the same dialect, that is, the Bangkok dialect. Following this assumption, the transcription of the materials of all four periods is based on the phonemic system of Bangkok Thai given at the end of this paper ${ }^{1}$.

\section{Structure of Thai deictic time markers}

Comrie (1985) proposed three classes of time expressions: lexical items, lexically composite expressions and grammatical categories. Since in Thai, time is expressed lexically, the third class is not relevant here.

\subsection{Lexical items as deictic time markers}

By lexical item, I mean a one-word structure. Based on the data of the four periods, deictic time markers of oneword structure can be grouped into two types: monosyllabic and non-monosyllabic words. The monosyllabic time markers are few in number. They are nii45 (SK, AY, RN, MT) (this) ' 'now', nan45 (SK, AY, RN, MT) (that) 'before', naa42 (SK, AY, RN, MT) (front) 'future', koon22 (SK, AY, RN, MT) (proceeding) 'before', mua42 (SK, AY, RN, MT) (point of time) 'when', dəəm33 (AY, RN, MT) (origin) 'before'. Except for the last two which can occur independently, these mono- syllabic time markers must co-occur with a preposition in a preposition phrase (see 1.2.2) or a noun in a noun phrase (see 1.2.1). Some of the preposition phrases developed into lexical time markers in later periods as discussed below. As can be seen, these monosyllabic time markers except for mua42 do not basically denote time. nii 45 , nan 45 are demonstratives; naa42 is a noun denoting a body organ, a face; koon 22 is an adverb meaning 'in front'.

Non-monosyllabic lexical time markers include bat22 nii45 'now' (SK, AY, RN, MT), mua42 kəon22 'before' (SK, AY,

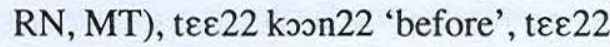
koon22 nii45 'before' (RN, MT), diaw24 nii45 'now' (RN, MT), phaay33 lan24 'later, time ahead' (AY, RN, MT), phaay33 naa42 'time ahead' (RN, MT), lan24 lan24 'recently' (MT). These lexical time markers either developed from noun phrases or preposition phrases.

from noun phrases:

i) bat22 nii45 < bat22 'breath' nii45 'this'

ii) mua42 koon22 < mta42 'point oftime'koon22 'precedingperiod'

iii) phaay33lan $24<$ phaay33 'side' lan24 'back'

iv) $\quad$ phaay33 naa $42<$ phaay33 'side' naa42 'front'

v) $\quad \operatorname{lan} 24 \operatorname{lan} 24<\operatorname{toon} 33 \operatorname{lan} 24 \operatorname{lan} 24$ $<$ toon33lan24<toon33 'portion' lạ24 'back'

from preposition phrases:

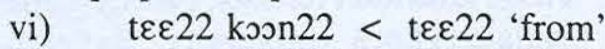
koon22 'preceding period' 
vii)

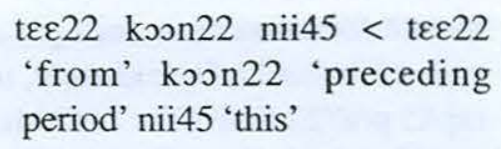

Some observations should be made here. First, from the Sukhothai period until now there has been an increase of lexical time markers in the nonmonosyllabic group. On the contrary, the mono-syllabic lexical time markers seem to be a closed class with members almost all of which do not occur independently. Secondly, some nonmonosyllabic time markers are analyzed as phrases in the Sukhothai period and probably in the Ayutthaya period. They have become lexical words, no longer analyzable synchronically, in the latter two periods. These include bat 22 nii 45 ,

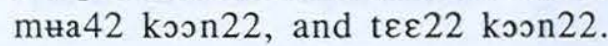
Thirdly, the noun phrases formed in the later periods show the use of nouns denoting a portion or a part as the head noun. These lexical time markers include phaay33 lan24 'in the future' with the head noun 'phaay33' meaning 'a side'; phaay33 naa42 'in the future' again with 'phaay33' meaning 'a side'; toon33 lan24 'afterwards' with the head noun 'toon33' meaning 'a portion'. Lastly, the reduplication in toon 33 lan 24 lan24 may illustrate that toon33 lan24 has not yet been finalized as a one-word time marker. lan24 lan24 which shows a further development from toon 33 lan24 $\operatorname{lan} 24$, however occurs as a one-word time marker. (see also 1.2.1 b) Fourthly, the time markers given here usually denote a stretch of time except bat 22 nii45 which means the present point of time. diaw24 nii 45 may denote either a point of time or a period of time, i.e. the present time.

\subsection{Lexical composites as deictic time markers}

Lexical composite deictic time markers can be grouped into two types of construction: a noun phrase, and a preposition phrase. Each construction displays several patterns. But although some new patterns are added, what actually gives variety is the introduction of new lexical items in the slots of the patterns.

\subsubsection{Noun phrase deictic time markers}

Noun phrase deictic time markers in the data of the four periods illustrate three main patterns:

a) temporal noun - demonstrative nii45/nan45

b) temporal noun - spatial noun naa42/ lan24 - direction word pay33/maa33

c) spatial noun - locative preposition - demonstrative pronouns nii45/nan45

\section{a) Temporal noun-demonstrative nii45/nan45}

viii) mta42 nan45 'the past' (SK, AY, RN)

ix) mua42 nii45 'the present' (SK, AY, RN)

x) chta42 nii45 'this life time' (SK)

xi) chuan42 nii45/nan45 'this/that period' (RN, MT)

xii) toon33 nii45/nan45 'this/that moment' (MT)

xiii) ra245ya245 nii45/nan45 'the present/past period' (MT) 
xiv) khə33 na?22 nii45/nan45 'at present/that time' (AY, RT, MT)

xv) wee33laa33 nii45/nan45 'the present/past time' (MT)

It can be seen that in the first slot, a variety of nouns occur. The data show that in the Sukhothai and Ayutthaya periods, only temporal nouns, mua42 'when', chua42 'life time', khə33 na222 'while' are used in this slot whereas in the Rattanakosin and Modern Thai periods, words with spatial notions as a portion toon 33 or distance ra?45ya?45 are introduced. The first nouns except mua42 usually denote a portion or a part in the stretch of time specified by nii45/ nan45. The last example, wee33laa33 nii45 (time-this) 'now' in Modern Thai illustrates a semantically indefinite temporal word which when modified by demonstrative nii45 denotes a specific portion of time i.e. the present time.

mua42 is interpreted as a noun in the Sukhothai and Ayutthaya period because of the evidence such as thuk 45 mua 42 'every time' where mua 42 is apparently a noun. In mua42 nan45/nii45 where nii 45 and nan 45 are demonstratives, mua42 nii45/nan45 denote the present period and the past period respectively. Because mua 42 could be followed by a noun or a noun phrase as in mua 42 chua42 phoo42 kuu33 (the time - the life time-father-I) 'in my father's life time', it is easy for mua42 to be grammaticalized into a preposition 'when' in later periods as in mua42 wee 331 laa33 pert22 - naa33li245kaa33 - wan33 nii45 (MT) (when-time-eight-o'clock-today) 'at 8 o'clock today'.

Another observation must be made for mua42. In the Ayutthaya period there were a great number of occurrences of mua42 followed by a verb phrase that ends with nan 45 , for example, mua42 rap45 pra?22 thaan33 - ?aa33 haan24 nan 45 - mii33 - khon33 - maa33 - duu33 - maak42 (when-eat-food-that-haveman-come-see-much) 'When eating, many people came to look at us'. Here it is likely that mua 42 was modified by a kind of verb nominal, with nan 45 a demonstrative adjective marking the construction a noun phrase.

\section{b) Temporal noun - spatial noun naa42/lay24 - (pay33/maa33)}

xvi) mua42 naa42 'the time ahead, the future' (SK, RN)

xvii) toon33 lan24 'recently' (MT)

$\mathrm{xviii)} \mathrm{toon33} \mathrm{laß24} \mathrm{lan24} \mathrm{'recently'}$ (MT)

xix) ra245ya245 lan24 'in the immediate past' (MT)

$\mathrm{xx}) \operatorname{tosn} 33$ lan24 maa33 in the recent past to now' (MT)

xxi) khaay42 naa42 pay33 'in the future' (MT)

This pattern appears most in Modern Thai and the lexical composites in this pattern have certain restrictions. One cannot have *toon33 naa42, *ra245ya? naa42 or khaan42 lan24 to convey temporal meaning. Because of the restriction, toon 33 lan24, khaan 42 naa42, ra245ya245 lan24 are likely to become compound words in later time. In fact, phaay33 lay24, first appeared in the Ayutthaya period, was most probably a noun phrase which has become in Modern Thai a non-monosyllabic lexical time marker (see 1.1.) This use of naa42 'front' and lan24 'back' with spatial 
notions illustrate the front/back orientation as will be discussed later in section 3 .

toon33 lan24 lan24 also found only in Modern Thai shows an extension of the construction where the spatial word is reduplicated. From this reduplicated expression, lan24 lan24 'recently', a lexical time marker is derived.

In the Rattanakosin period maa33 'come' and pay33 'go' appears after the non-monosyllabic temporal nouns such as phaay33 lan24 maa33 (recent pastcome) 'later (in the past)'. From then, temporal expressions meaning a period of time may be followed by pay 33 or maa33 with temporal relation to the present time, if not otherwise specified (see Section 3); thus we have khaan42 naa42 pay33 (future - go) 'in the future'.

\section{c) Spatial noun - locative preposition - demonstrative pronoun nii45/nan 45}

Deictic time markers of this type are found only in Modern Thai data. These are:

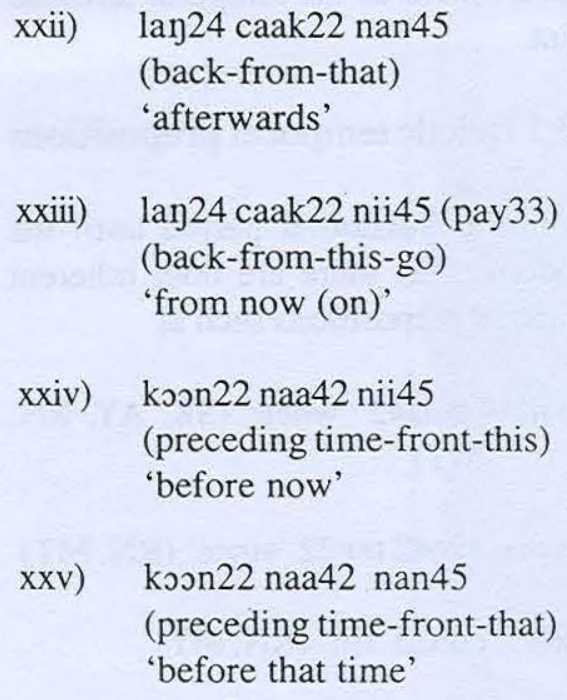

These time markers are best explained by means of metaphor i.e. the back of the referential time, nan 45 or the front of the referential time, nii45. It should be pointed out here that there are prepositions lan24 caak22 'after' and koon22 'before' used in Modern Thai, for example:

1) $\quad \operatorname{la\eta } 24$ caak22 - son 24 khraam33 - look42 - khraj45 thii 42 - soon 24 (after-war-world-time-two) 'After World War II'

2) koon 22 naa42 - $2 u ? 22$ bat 22 ti?22 heet22 - khraj45 nan45 (before-accident-time-that) 'Before that accident'

Considering the structure of the deictic time markers proposed above, i.e. spatial noun - locative preposition demonstrative pronouns nii $45 /$ nan 45 , it is reasonable to say that the prepositions are derived from the temporal noun phrases rather than the other way around; general considerations of grammaticalization paths would also suggest this.

\subsubsection{Preposition phrase deictic time markers}

By preposition phrase deictic time markers, I mean the preposition phrases that occur as composite units functioning as time adverbials for example,

3) tєع22 nan45 maa33 - khaw24 ko242 - may22 - maa33 - ?iik22 - ləəy 33

(since then-he-not-come-again -not any more-then)

'Since then he never came again.' 
Preposition phrase deictic time markers usually contain nii 45 'this' or nan 45 'that' which are analyzed here as demonstrative pronouns. A few preposition phrase deictic time markers contain naa42, a noun meaning 'face' or 'the front part'. The preposition phrase deictic time marker in the Sukhothai period illustrated a particular pair of preposition: t $\varepsilon \varepsilon 22$ (from)...mtra33 (to) as in tع£22 nii45 mua33 naa42 'from now till the time ahead'. In the Ayutthaya period, this preposition

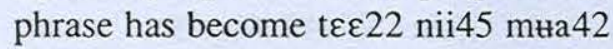
naa42 with a change of tone in mta33. Following are some preposition phrase time markers that appear in the last two periods studied.

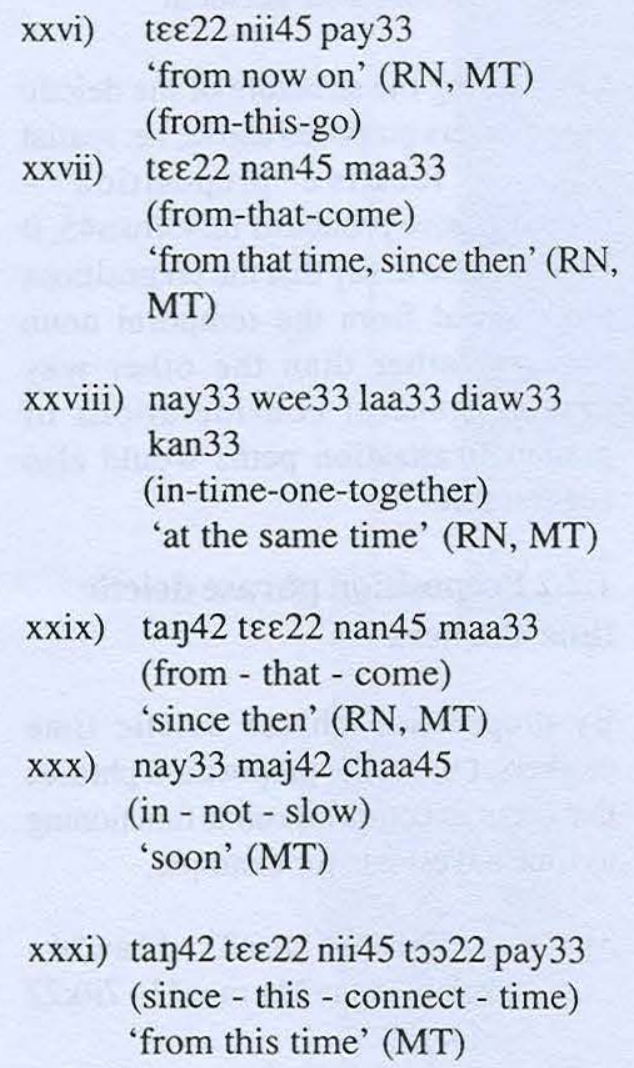

As can be seen, most time markers above contain the initial boundary or the

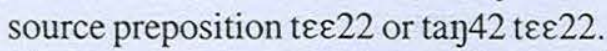
The time marker nay 33 may 42 chaa 45 first appeared in Modern Thai seems to be a loan translation from an English expression 'in no time'.

\subsection{Deictic temporal prepositions and subordinators}

Most deictic time markers discussed above contain the words nii 45 'this' or nan 45 'that' which serve as the temporal referential point for the temporal interpretation. nii45 'this' is interpreted as coinciding with the present time. nan 45 'that' refers to the time mentioned earlier in the text and usually it is the time before the present time. Some time markers such as phaay 33

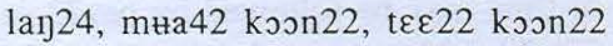
which do not contain the words nii 45 and nan 45 , unless specified otherwise, refer to the location time of the utterance as the temporal referential point. The deictic temporal prepositions and subordinators are different. They mark the noun or noun phrase, in case of preposition, or the subordinating clauses in case of subordinators, as the temporal referential point. For example, in the deitic temporal preposition th 124 diaw24 nii45 'until now' tht124, marks diaw24 nii45 as the temporal terminal point.

\subsubsection{Deictic temporal prepositions}

From the Sukhothai period until the modern time, there are both inherent temporal prepositions such as

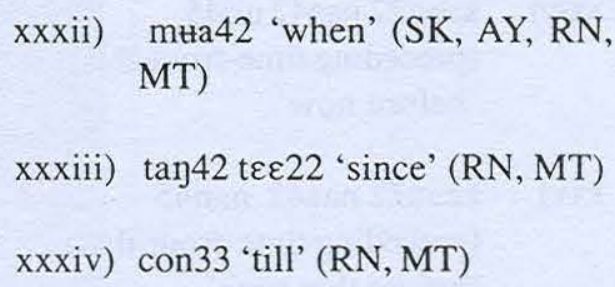
MT)

xxxiii) $\tan 42$ teع22 'since' (RN, MT)

xxxiv) con33 'till' (RN, MT) 
and grammaticalized temporal preposi-

tions such as

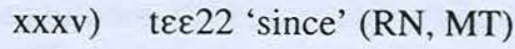

xxxvi) naj33 'in' (AY, RN, MT)

xxxvii) caak22 'from' (MT)

xxxviii) then24 'to, till' (MT)

thun24 and caak22 are inherent verbs meaning 'to arrive' and 'to depart'. They have been grammaticalized into locative prepositions 'to' and 'from' respectively. As derived temporal markers, they convey the meanings of terminal point and initial points of time respectively. nay33 'in', a locative preposition, grammaticalized from a noun, is similarly used as a temporal preposition. tع£22 is most probably grammaticalized from a borrowed Burmese verb meaning 'to begin'.

\subsubsection{Deictic temporal subordinators}

As has been mentioned, temporal subordinators mark the subordinating clause immediately after them the temporal reference to the event in the main clause of a complex sentence. From the data thirteen temporal subordinators are seen:

xxxix) mнa42'when' SK AY RN MT

xl) tiam33 teع22 'since' SK - - .

xli) khran45 'when'
- AY RN -

xlii) kwaa22 'till'

- AY RN MT xliii) con33 'until'

- AY RN MT

xliv) phəo33 'when, as soon as'

- AY RN MT

xlv) con33 kwaa22 'until'

- $\quad$ RN MT

xlvi) khə33 na222 'when, while'

- $\quad$ RN MT

xlvii) koon22 'before'

- - RN MT

xlviii) lan24 caak22 'after'

- - - MT

xlix) koon22 naa42 'before'

- - - MT

1) wee33 laa33 'when'

- - - MT

li) $\operatorname{ton} 33$ 'when'

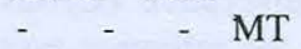

As can be seen from the list above, only mta 42 has been used as a temporal subordinator until now since Sukhothai

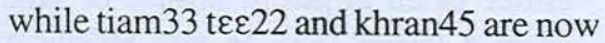
obsolete. Besides, several subordinators are synonyms, for example mta 42 , khran45, wee33 laa33, toon33 all mean 'when'. Moreover, several temporal subordinators are made up from a combination of two synonymous words such as con33 kwaa22 both of which mean 'till' or they are derived from noun phrase such as laj24 caak22 from lan24 caak22 nan45, koon22 naa42 from koon22 naa42 nan45. In Modern Thai, a temporal noun as wee33 laa33 'time' and toon33 'period of time' are also used as temporal subordinators. Below are examples of the temporal subordinating clauses in complex sentences: 
4)

$$
\begin{aligned}
& \text { toon } 33 \text { - khaw } 24 \text { - hok22 lom } 45 \\
& \text { - chan } 24 \text { - may42 - yuu } 22 \text { - } \\
& \text { baan42 } \\
& \text { (time-he-fall-I-not-stay-home) } \\
& \text { 'When he fell, I was not home.' }
\end{aligned}
$$

5)

$$
\begin{aligned}
& \text { mua42 - kuu33 - khtn } 42 \text { - yay } 22 \\
& \text { - day } 42-\operatorname{sip} 22 \text { kaaw } 42 \text { - } \\
& \text { khaw } 42, \ldots \\
& \text { (when-I-up-big-get-nineteen- } \\
& \text { year,...) } \\
& \text { 'When I was nineteen years } \\
& \text { old,...' }
\end{aligned}
$$

\section{Semantic types of deictic time markers}

In order to locate an event in a time line, a temporal point of reference is needed. The deictic temporal point of reference linguists usually mention is the zero point of reference (Comrie, 1985; Lyons, 1995) which coincides with the present moment (Comrie, 1985) or the locution time of utterance (Lyons, 1995). However, the reference point needed not always have to coincide with the locution time of utterance, it can be another event identifiable in a context either in an adjacent phrase or clause or in a larger text. In this article two types of temporal reference point are also proposed: the locution time of utterance or in this paper the time when the text was written, and the text time reference which in this paper can be found in the subordinating clause or phrase or assumed to be in the unseen texts. Comrie (1985) called the first type of temporal reference the absolute time reference and the second, the relative time reference. Comrie's terms will be adopted because they are generally known but from time to time, the terms 'text time reference' will be used for the latter type of reference.
In discussing semantic types of temporal relations or connections between the main clause and its subordinating clause in English, Givon (1993) mentioned altogether eight types of relations. They are given here with an example of the temporal subordinator which conveys the semantic type in the blanket: precedence (before), subsequence (after), simultaneity (while), point coincidence (as), terminal boundary (till), initial boundary (since), and intermediacy (between). He also mentioned 'when' as a generic time subordinator which can convey several semantic relations, for example, 'when' can indicate subsequence as well as simultaneity:

When he left home, she felt ill. (Subsequence)

When she walked back home, it started to snow. (Simultaneity)

We will use these terms with some modifications. First, in connection with the terms 'precedence' and 'subsequence', we will use Kortmann's (1997) terms 'posteriority' and 'anteriority' respectively instead. The reason is that the two terms given by Kortmann are consistent with the other terms in the set in the manner that the semantic types now are all marked at the temporal expressions. Secondly, we will include 'point coincidence', 'intermediacy' and 'simultaneity' under the same term 'simultaneity'.

Thus, in discussing semantic types of the deictic time markers either as absolute time reference or relative time reference, we will be referring to the following semantic types as follows: anteriority, posteriority, simultaneity, terminal boundary, initial boundary and 
generic 'when'. These terms are primarily Givon's terms (1995) with some terms introduced by Kortmann (1997).

\subsection{Absolute time reference}

As mentioned above, when the temporal point of reference coincides with the present moment or relative to the present moment, we have the absolute time reference. In Thai, this is usually displayed by the inclusion of nii 45 in the time markers. However, some of the time markers in this type do not have nii45, especially those in the anteriority sub-type. Five sub-types are identified: simultaneity, anteriority, initial boundary, posteriority and terminal boundary.

\subsubsection{Simultaneity}

When the time of the time markers is the same time as that expressed in the locution time, we have the simultaneity semantic type, for example in

6) bat22 nii45 - phom 24 - khos24 pəat22 - kaan33 pra222 chum 33 (now - I - request - open meeting)

'Now I would like to declare open the meeting.'

the event 'open the meeting' occurs at the time bat22 nii45 'now' which coincides with the locution time. Following is the time markers in this sub-type with the indication of the periods they are found.

lii) bat22 nii45 SK AY RN MT

liii) chua42 nii45 SK
liv) mษa42 nii45 SK AY RN -
lv) mua42 lun33 nii45
SK AY
lvi) diaw24 nii45
- - RN MT
lvii) toon33 nii45
- $\quad$ - RN MT
lviii) chuaß42 nii45
- $\quad$ - RN MT
lix) wee33 laa33 nii45
- $\quad$ - RN MT
Ix) khə33 na222 nii45
- - RN MT
1xi) pat22 cu33 ban33 nii45

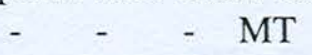

It can be seen that some of the time markers in the simultaneity sub-type are now obsolete and many are introduced in the two latter periods. Two sub-types can be distinguished in simultaneity. One is 'the point of time' sub-type. The other is 'the period of time' sub-type. In the Sukhothai period, bat 22 nii 45 seemed to indicate the second sub-type. It has been changed to the first sub-type in Modern Thai. diaw 24 nii 45 can be in either subtype whereas the rest of the markers in the above list are in the second sub-type.

\subsubsection{Posteriority}

When the event in the sentence occurred before the locution time we have the posteriority type, for example in, 


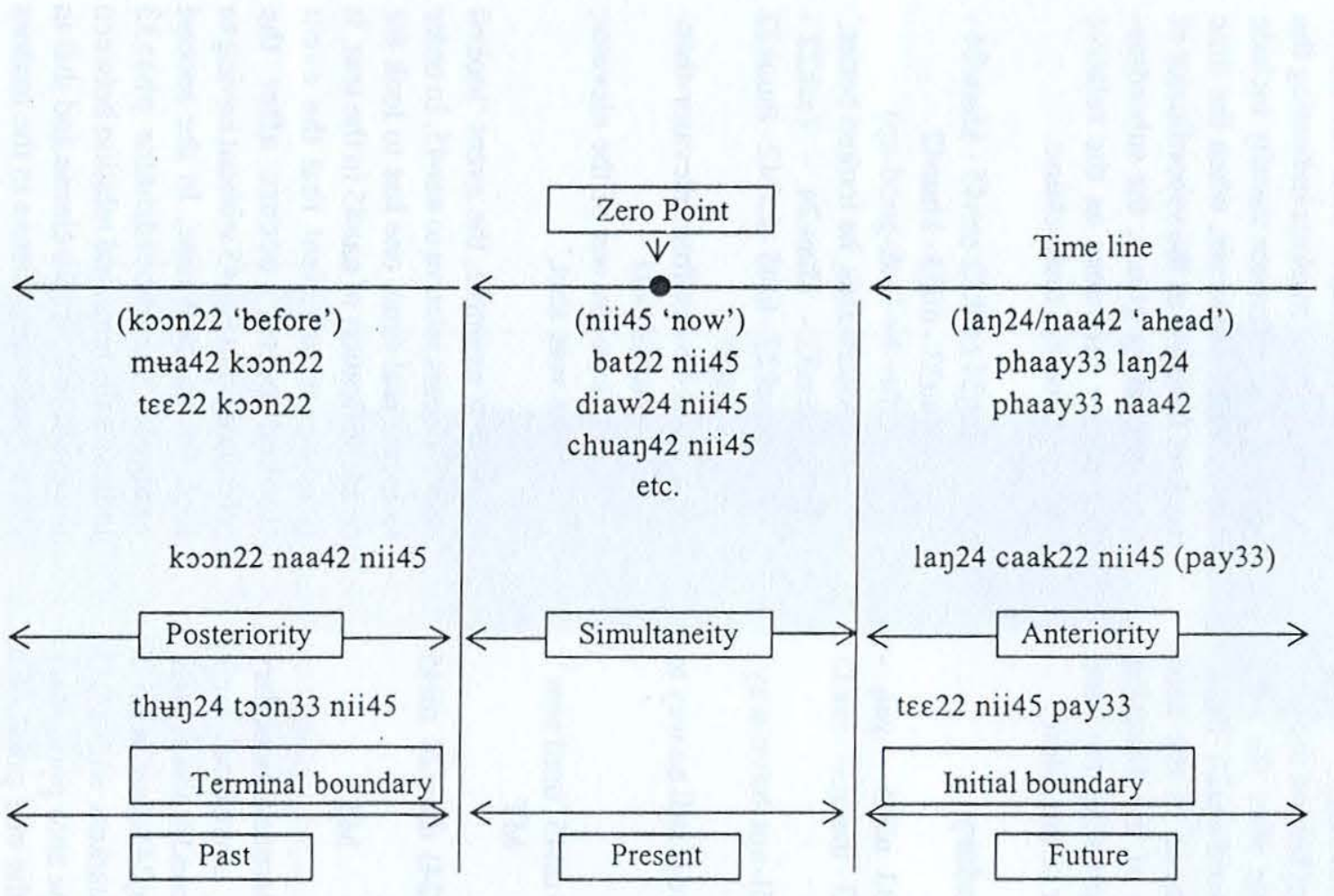




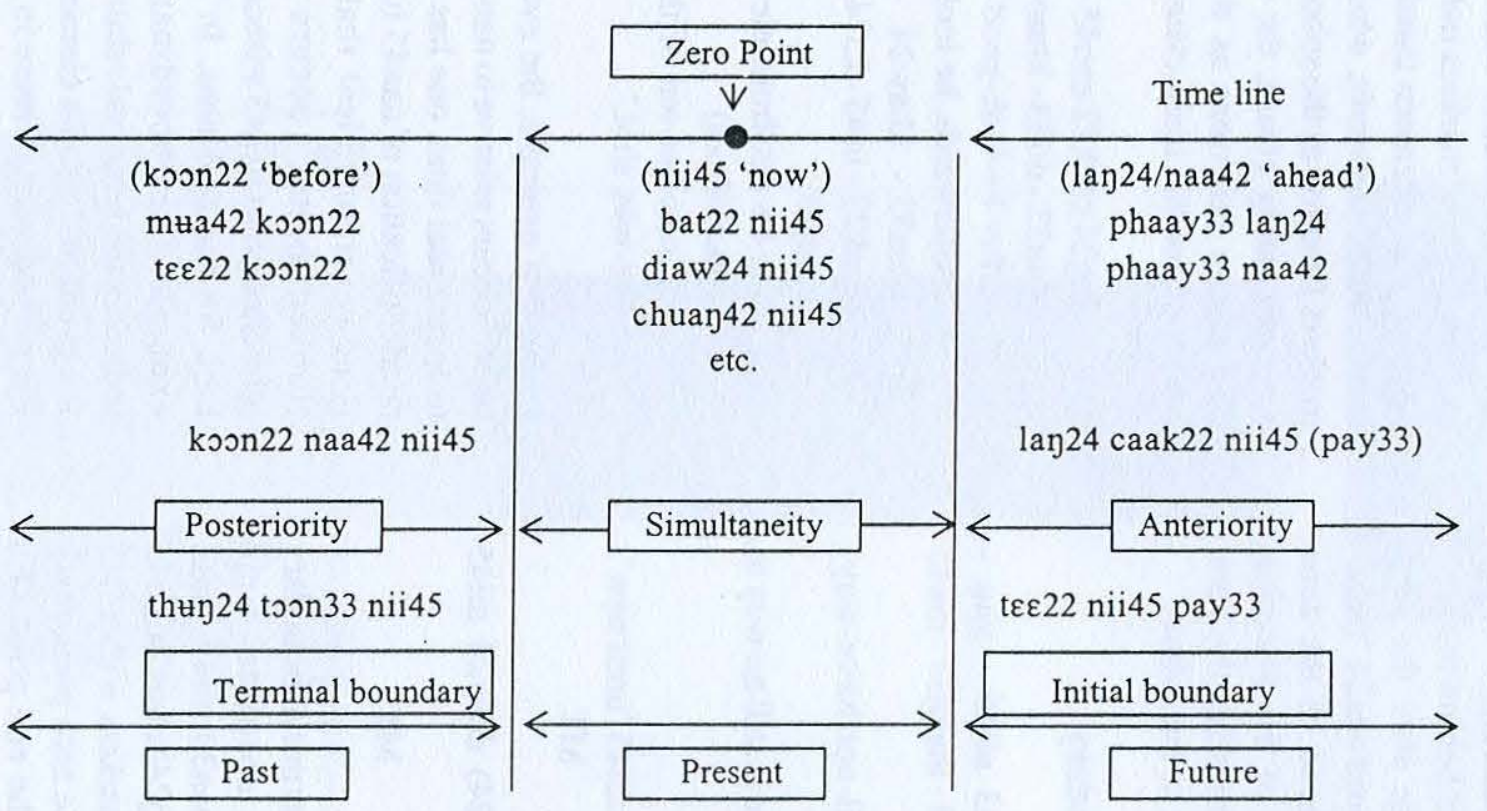




\subsubsection{Simultaneity}

Some examples are given here:

13)

nay33 - wee33 laa33 - nan45 -

may 42 - mii33 - khray 33 - yuu 22

- baan42

(in-time-that-not-have-whostay-home)

'At that time, no one was home.'

14) khaw24 - thuuk22 - yin33 ra245 waan22 - khap22 - rot45 - pay33 - hua24 hin24 (he-touch-shoot-betweendrive-car-go-Huahin)

'He was shot while he was driving to Huahin.'

lxxviii) nay33 wee33 laa33 nan45 'at that time'

- - - MT

lxxix) ra245 waan22 nan45 'during that time'

- - RN MT

lxxx) chuay42 nan45 'in that period of time'

- - - MT

lxxxi) khə33 na?22 nan45 'during that time'

- - - MT

lxxxii) khə33 na?22 (subordinator) 'while'

- - RN MT

lxxxiii) phoo33 (subordinator) 'as soon as'

- - RN MT

lxxxiv) ra245 waan22 (subordinator)

'while, as soon as'

- - - MT
In the first example which is an example sentence, the event, yuu 22 baan 42 'stay home' occurred at the same time as nan 45 'that' serving as a relative time reference. In the second sentence, the event in the subordinating clause with ra245 waan22 as a subordinator occurs at the same time as the event in the main clause. In other words, the subordinating clause serves as the reference temporal point. Again, some time markers indicate a point of time (phoo33, khə33 na?22) while others mark the stretch of time (nay33 wee33 laa33 nan45, ra245 waan22). The relative reference time markers of the simultaneity type were hardly found in the first two periods whereas in the latter two periods they are plenty.

\subsubsection{Posteriority}

15) nat45 - phop45 - nay33 - rta33

- koon22 - rta33 - ?ook22

(appointment-meet-in-shipbefore-ship-out)

(We) made an appointment to meet in the ship before it left the port.

lxxxv) koon22 naa42 nan 45 'before that time'

- $\quad$ - $\quad$ - MT

lxxxvi) koon22 naa42 nan45 khtn42 pay33 'before that time'

- $\quad$ - $\quad$ MT

1xxxvii) kəon22 (subordinator) 'before'

\section{- AY RN MT}

The posteriority time markers listed above indicate that the temporal relative reference point nan 45 occurred in the past after, or in subsequence to the event in the simple sentence. Similarly, the event in the subordinating clause 
with kəon 22 as the subordinator occurred post or after the event in the main clause. In Givon's terms, the event in the main clause preceeded the termporal relative reference nan 45 .

16)

$$
\begin{aligned}
& \text { koon } 22 \text { - naa } 42 \text { - nan } 45 \text { - chan } 24 \\
& \text { - yuu } 22 \text { - chian } 33 \text { may } 22 \\
& \text { (before-that-I-stay-Chiangmai) } \\
& \text { 'Before (that) I stay in } \\
& \text { Chiangmai.' }
\end{aligned}
$$

Between koon22 naa42 nan45 and koon 22 naa42 nan 45 khun 42 pay 33 , the latter indicates the event deeper in time before the relative reference nan 45 . (see Section 3)

\subsubsection{Anteriority}

17) khaw24 - klap22 - baan42 lan24 - caak22 - soop 22 - set 22 (he-return-home-afterexamination-finish)

'He went back home after he finished with his exam.'

lxxxviii) lan24 caak22 nan45 'after that'

- $\quad$ RN MT

lxxxix) lan24 caak22 nan45 maa33 'after that' (past)

- - - MT

xc) lan24 caak22 nan 45 pay33 'after that' (future)

- $\quad$ - MT

xci) too22 maa33 phaay33 lay24 'after that, afterwards'

- - - MT

xcii) lan24 caak22 (subordinator) 'after'

- $\quad$ - RN MT
Although, nan 45 marks the time anterior to the event involved, it does not have to only refer to the anterior time in the past but it can be used to refer to the time ahead in the future. In other words, it only marks subsequent event from nan 45 whether or not nan 45 refers to the past or future event:

(raw33 - ca222 - pay33 - thun24 - room33 - wan33 - can33 naa42) lan24 - caak22 - nan45 2iik22 - soon 24 - wan 33 - cun33 - ca222 - paj33 - paa33 riit42 (we-will-go-arrive-RomeMonday-next) back-from-thatmore-two-day-so-will-go-Paris '(We will arrive in Rome next Monday.) Two days after that, we will go to Paris.'

19) lạ24 - caak22 - nan45 - maa33

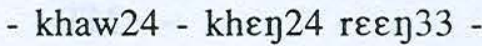
khun 42

(back-from-that-come-hestrong-up)

'After that time/afterwards he became stronger.'

Sentence 18 and 19 show that nan 45 'that' can be a relative time reference before the zero point or after the zero point, depending on the context. If the context is not specified, the common interpretation would be that nan 45 'that' indicates the time before the zero point and if specified, nan 45 refers to the point of time in the future. It must be observed that pay33 'go' and maa33 'come' help mark the time in the future and the time in the past respectively.

\subsubsection{Initial boundary}

Initial boundary subordinators found in

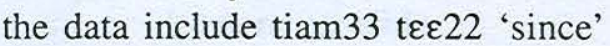
which was used only in the Sukhothai 


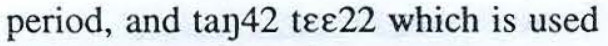
in the later periods, for example:

$$
\begin{aligned}
& \text { phii42 - phta24 - phuu42 - } \\
& \text { 2aay42 - taaj33 - caak22 - } \\
& \text { phua24 - tiam33 teع22 - yay - } \\
& \text { lek45 } \\
& \text { (brother-we-man-eldest-die- } \\
& \text { from-us-since-still-small) }
\end{aligned}
$$

21)

$$
\begin{aligned}
& \tan 42 \text { - teع22 - khaw24 - maa33 } \\
& \text { - thəə33 - ko?42 - dii33 - khun42 } \\
& \text { (since-he-come-she-then-good- } \\
& \text { up) }
\end{aligned}
$$

'Since he came, she has become better.'

Besides subordinators, a preposition

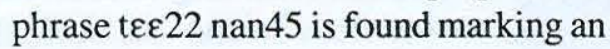
initial boundary.

$$
\begin{aligned}
& \text { tع\&22 - nan45 - maa33 - thuk45 } \\
& \text { - khon33 - ks242 - mii33 - } \\
& \text { khwaam } 33 \text { suk22 } \\
& \text { (from-that-come-every-man- } \\
& \text { then-have-happiness) } \\
& \text { 'From that time on, everyone } \\
& \text { was happy.' }
\end{aligned}
$$

\subsubsection{Terminal boundary}

This semantic type is found only in a complex sentence marking the temporal relations between the events in the main clause and a subordinating clause. The subordinating clause conveys the terminal boundary, for example:

23) thon 33 - yuu 22 - kwaa22 - ca222 - $\sin 42$ - ?aa33 yu245 (AY) (endure-stay-till-finish-age) '(They have to) endure until their lives end.'

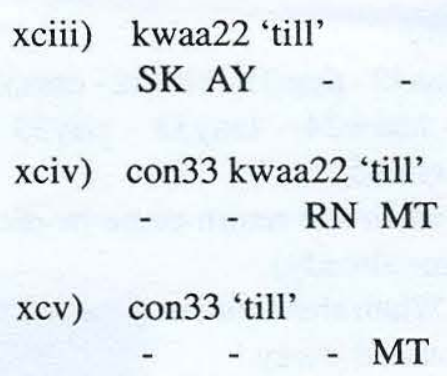

In Modern Thai, kwaa22 does not convey the terminal boundary but posteriority, for example:

24)

$$
\begin{aligned}
& \text { kwaa22 - khaw24 - ca222 - } \\
& \text { klap22 - luuk42 - kə242 - lap22 } \\
& \text { - lęw45 (MT) } \\
& \text { (before-he-return-child-then- } \\
& \text { asleep-already) } \\
& \text { 'Before he returned, his child } \\
& \text { has already fallen asleep.' }
\end{aligned}
$$

\subsubsection{The generic When}

mнa42 can convey several temporal meanings: simultaneity, anteriority, posteriority, for example:

Simultaneity:

25) mua42 - chua42 - phoo42 kuu33 - kuu33 - bam33 rəə33 -

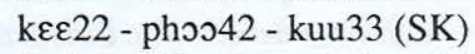
(when-life-time-father-I-Iplease-to-father-I)

'During my father's life time, I pleased him.'

Anteriority:

26) mua42 - khaw24 - taay33 lon33, baan42 - ko?42 - thuuk22 - khaay24 (MT) (when-he-die-down-housethen-touch-sell)

'When/after he passed away, the house was sold.' 
Posteriority:

27) mua42 - thəə33 - klap22 - maa33 - khaw24 - taay33 - pay33 leहw 45

(when-she-return-come-he-diego- already)

'When she returned, he already passed away.'

In fact, there is no need to have distinct subordinator for the above semantic types. The context itself indicates which event occurred before or after or at the same time. Probably because of that, temporal subordinators were few in the earlier periods.

Besides mua42, the Ayutthaya period displayed khran45, and phos33, both of which can also denote several semantic relations. phoo33 is still used in Modern Thai whereas khran 45 is now obsolete.

\section{Deictic markers and concept of time}

In this section deictic time markers will be studied in terms of metaphors to see how time is conceived by the Thais. Fillmore (1977) mentioned two types of time metaphor in English in connection with time deixis. The first is the moving time metaphor in which time is the moving object. The other is what I call the standing time metaphor in which the time is a static object. The study of deictic time markers in Thai also shows these two types of metaphors with different orientations.

\subsection{The moving time metaphor}

When the following set if deictic time markers are examined, two groups can be distinguished on the basis of the words kəon22 'preceding' and lan24 'behind, back':

\author{
xcvi) tع๕22 kəon22 'before' \\ xcvii) mua42 kэon22 'before’ \\ xcviii) wan33 kəon22 'the previous \\ day(s)' \\ xcix) phaay33 lan24 'future' \\ C) wan33 lan24 'future'
}

Considering that all deictic time markers above with koon 22 convey the past time or the preceding time and all deictic markers with lan24 convey the future or the time to come, it is reasonable to think of time as moving object. If a speaker stands with his face in the same direction as the a moving time and the time moves from behind his back, the time that he sees must be that which passed him and preceded him. The time behind his back is unseen, he can refer to it as the time behind: phaay33 lan24 (side-back), wan33 lan24 (day-back). Because the time has yet to pass him, it is in the future. The following diagram illustrates the moving time and the speaker orientation.

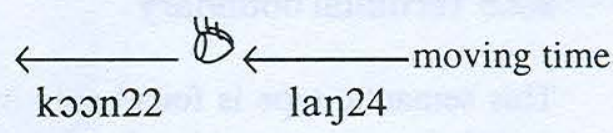

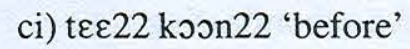

cii) m+a 42 koon 22 'before'

ciii) wan33 koon 22 'the previous day(s)'

civ) phaay33 lan24 'future'

cv) wan33 lan24 'future' 
If the speaker changes his orientation and turns his back to the past, facing the moving time, he will now see the future as the time ahead. The deictic time marker phaay33 naa42 (sideahead) 'future' illustrates the moving time metaphor with the new orientation. toon33 lan24 'the past' and lan24 lan24 'recent past' also illustrate the past in the new orientation.

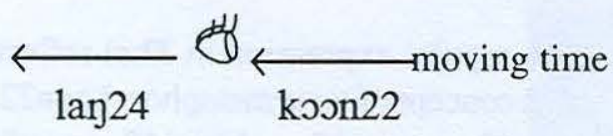

cvi) toon33 lan24 'past time'

cvii) lan24 lan24 'past time'

cviii) phaay33 lay24 'past time'

cix) phaay33 naa42 'future'

cx) (wan33 naa42 'future')

\subsection{The standing time metaphor}

Time is always moving but we can freeze a portion on the real time line. When we do this, we have the standing time metaphor. The following sets of deictic markers indicate two static temporal points: nan 45 'that' and nii 45 'this'

\begin{tabular}{|c|c|}
\hline cxi) & $\begin{array}{l}\text { lay24 caak22 nan } 45 \\
\text { lan24 caak22 nii45 }\end{array}$ \\
\hline cxii) & $\begin{array}{l}\text { koon } 22 \text { naa42 nan } 45 \\
\text { koon22 naa42 nii } 45\end{array}$ \\
\hline cxiii) & $\begin{array}{l}\text { caak22 nan } 45 \text { maa33 } \\
\text { caak22 nii } 45 \text { pay } 33\end{array}$ \\
\hline ) & $\begin{array}{l}\operatorname{ta} 42 \text { t } \varepsilon \varepsilon 22 \text { nan } 45 \text { maa } 33 \\
\tan 42 \text { t } \varepsilon \varepsilon 22 \text { nii } 45 \text { pay } 33\end{array}$ \\
\hline
\end{tabular}

The words lan 24 'back' and naa42 'front' indicate the back portion and front portion of the static points nan 45 and nii45. The time is moving in the same direction as in the first type of metaphor only in this metaphor, we stop it for the purpose of sequencing the events. The words caak 22 and $\tan 42$ tع£22 seem to confirm the static status of the reference points: $\operatorname{lan} 24$ caak22 nan 45, (the back portion from that), 'after that, afterwards'. Because nii45 'this' is usually conceived as the present time, lay24 caak22 nii45, caak22 nii45 pay33, $\tan 42$ t $\varepsilon \varepsilon 22$ nii 45 pay33 refer to time beyond the present or time in the future.

The direction word maa33 'come' and pay33 'go' seem to give the direction towards and from the zero point. This is evident from the fact that the time markers denoting the past can co-occur with maa33 except for *koon22 naa42 nan 45 maa33 and *koon 22 naa42 nii 45 maa33. The time markers denoting the time in the future can co-occur with pay33 'go' and not with maa33 'come'. We can explain why *koon22 naa42 nii45 maa33 is not acceptable. This is because nii45 is the zero point and therefore there is no distance for maa33. As for *koon22 naa42 nan 45 maa33, it is probable that the time is too remote from the nii 45 point and maa33 does not seem possible. The following diagram is an attempt to illustrate the standing time metaphor: 


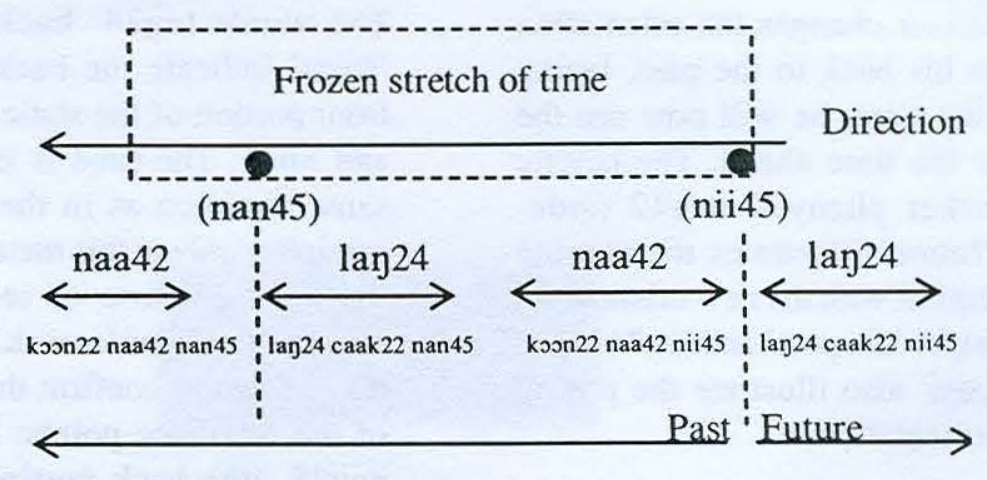

\subsection{The time layer metaphor}

So far we have the horizontal axis of time, which gives us the picture of a sequence of events. However, we also conceive time in a vertical line with the previous the 'above' the present time.
A temporal expression in Thai reflects this concept of time metaphor: koon22 naa42 - nan45 - khtn42- pay33 (preceding-that-up-go) 'Before the past period, the remote past period'. The vertical axis reflects the layers of the periods and again pay33 is used as the time far away from the speaker.

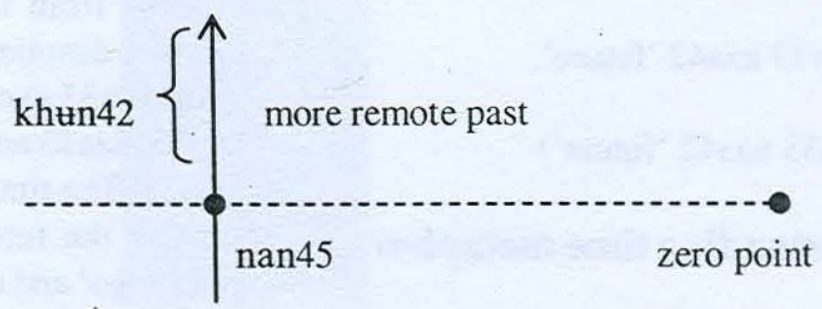

If we look at the list of time markers, we can see that we have more expressions for the present and the past. This may reveal that a Thai speaker seems familiar with the present and the past and therefore, has more temporal expressions to refer to. With less expression for the future, it probably means that he has no experience with the future and thus has no necessity to refer to them in details. It is also apparent that the concepts of time revealed by the moving time metaphor and the standing time metaphor serve as the basis for the coining of new deictic temporal expressions in modern Thai.

\section{Conclusion}

In conclusion, the study of time markers from the four periods show that time markers in Modern Thai are larger in number than those in the other periods. In fact, there was a sharp increase already in the Rattanakosin period. The time markers in the two latter periods especially in Modern Thai show not only more time markers but also the longer time markers. The long time markers are either doublets such as con33 kwaa22 'until' or phrases such as too 22 pay33 khaaj42 naa42 'in the future'. Phrasal time markers can be either noun phrases such as lan24 caak22 nan45 
'afterwards' or preposition phrases such as $\tan 42$ t $\varepsilon \varepsilon 22$ nan 45 maa33 'from that time, since then'

It is seen that in the Sukhothai period demonstrative pronouns nii 45 and nan 45 and the noun meaning 'face' have been extended to give temporal meanings. From the Ayutthaya period nouns denoting a distance have been used in temporal expressions. In Modern Thai, grammaticalized prepositions from verbs such as caak22 'from', thum 24 'to' are used also as time markers. Thus it can be said that words are added more and more to the time marker lexicon and only few words are obsolete. As a result, synonyms in time markers are not rare. For 'now', one may have bat22 nii45, diaw24 nii45, toon33 nii45, ra245 ya45 nii45, wee33 laa33 nii45; for future, one may have wan33 lan24, wan33 naa24, phaay33 naa42, khaay24 naa24 tos 22 pay33, tos22 pay33 khaar 24 naa24,

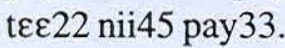

How time is conceived in modern Thai is not different from that of the Sukhothai period, that is, time is conceived as an entity moving from the back of a speaker or moving facing him; or as a stand still entity with the referential point nii45 'this' and nan45 'that'. However, elaborations of these concepts are apparent. One may now refer to the event as behind or in front of the referential point and close to or far from the zero point.

It is interesting to observe that mua42 equivalent to 'when' in English can convey several semantic temporal types. Moreover, it can be used to mark not only time but conditioning or reason such as in
28) mua 42 - khaw 24 - may 42 - thoj 42 nay24 sut 24 - khaw24 - ks242 - khoந33 - soop22 - tok22

(since/if-he-not-read-book-he-then-failexamination-fall)

'Since he does not review his lessons, he will probably fail the examination.'

Although this is interesting to probe into, it is far beyond the scope of this paper.

\section{Notes}

I would like to express my deep appreciation for the helpful comments given by Professor Bernard Comrie and Associate Professor

3 Kingkarn Thepkanjana who have both kindly spent their precious time reading through the original paper.

I also would like to thank Professor Shoichi Iwasaki, the organiser of SEAL XIII, for allowing me to publish the paper in Manusya.

${ }^{1}$ The Modern Thai phonemic system given here is for a broad transcription used in this paper.

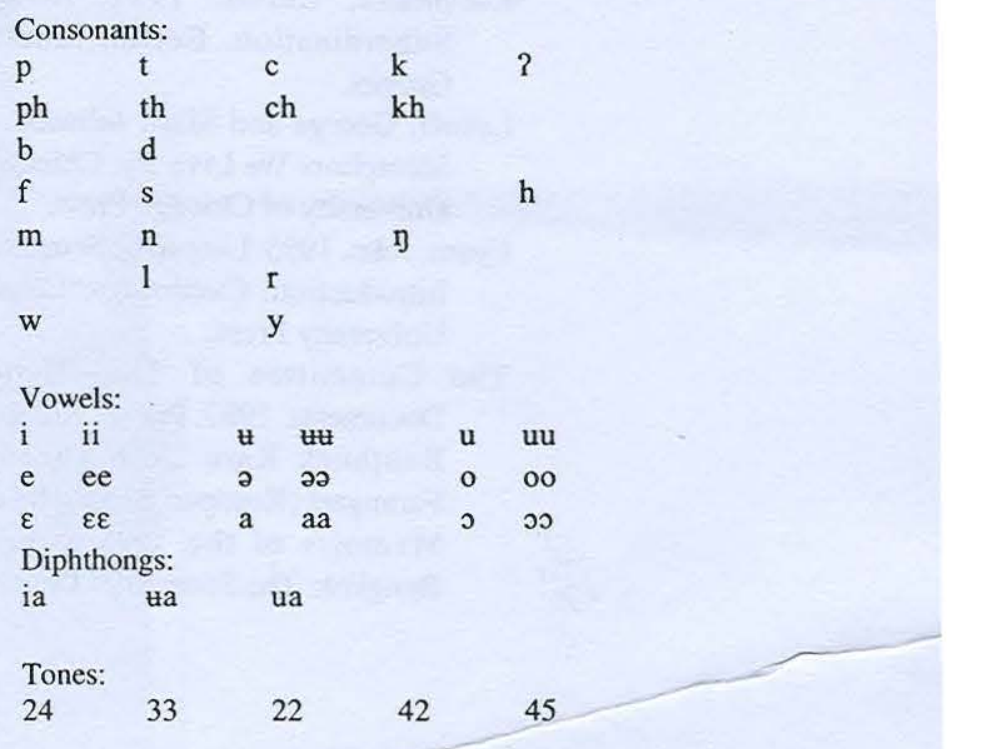


These tones correspond to the following Proto-Tai tones respectively: $\mathrm{A} 1 \mathrm{H}, \mathrm{A} 1 \mathrm{M}$ A2,B1-DS1-DL1, B2-C1-DL2, C2-DS2

${ }^{2}$ Inherent meaning of the word is given in bracket, the temporal meaning in inverted commas is secondary.

\section{References}

Comrie, Bernard. 1985. Tense. Cambridge: Cambridge University Press.

CU Concordance. 2002. Department of Linguistics, Faculty of Arts, Chulalongkorn University.

Fillmore, Charles J. 1997. Lectures on Deixis. Stanford: Center for the Study of Language and Information.

Fine Arts Department. 1964. Announcements in the Reigns of King Rama IV and V. Bangkok: Prachan Publishing House.

Fine Arts Department. 1998. Rama V's Letters to His Daughter: Klay Baan. The reprinted version. Bangkok.

Givon, T. 1993. English Grammar, A Functional-Typological Introduction Vol.II. Amsterdam: John Benjamins Publishing Company.

Kortmann, Bernd. 1997. Adverbial Subordination. Berlin: Mouton de Gruyter.

Lakoff, George and Mark Johnson. 1980. Metaphors We Live By. Chicago: The University of Chicago Press.

Lyons, John. 1995. Linguistic Semantics, An Introduction. Cambridge: Cambridge University Press.

The Committee of Thai Historical Documents. 1987. Prawat Kosapan Lae Banthuek Karn Dern Thaang Pay Farangset (Kosapan Biography and his Memoirs of the Trip to France). Bangkok: The Secretariat Department. 